\title{
Teletrabalho versos Qualidade de Vida: Uma Abordagem sobre as Experiências Vividas por Servidores do Tribunal de Justiça do Estado do Amazonas
}

\author{
Telework verses Quality of Life: \\ An Approach on Experiences Lived by Public Sever of the Amazonas State Court of Justice
}

Teletrabajo versus Calidad de Vida:

Una aproximación a las experiencias vividas por servidor público de la Corte de Justicia del Estado de Amazonas

\begin{abstract}
Rosinete Pereira Alves ${ }^{1}$ rosimanaus@hotmail.com http://lattes.cnpq.br/1851323027679046 https://orcid.org/0000-0003-2464-1649

Maria da Gloria Vitório Guimarães ${ }^{1}$ gloriavitorio@gmail. http://lattes.cnpq.br/3086221152758606 https://orcid.org/0000-0003-4610-8124
\end{abstract}

Recebido em: 12/09/2019 / Revisão: 27/09/2019 / Aprovado em: 31/08/2020

Editores responsáveis: Prof. Dr. Antônio Giovanni Figliuolo Uchôa e Prof. Dr. Jonas Fernando Petry

Processo de Avaliação: Double Blind Review

DOI: $\underline{\text { https://10.47357/ufambr.v2i3.6379 }}$ 
Teletrabalho versos Qualidade de Vida: uma Abordagem sobre as Experiências Vividas por Servidores do Tribunal de Justiça do Estado do Amazonas

\title{
Resumo
}

Objetiva-se analisar a percepção de pessoas que realiza parte ou totalidade do seu trabalho à distância das organizações empregadoras, fazendo uso de mídias de tecnologia. Especificamente, busca-se verificar se há melhoria na satisfação da pessoa que opta pelo trabalho remoto, bem como, vantagens e desvantagens do trabalho remoto. A busca pela qualidade de vida é um tema atual e tem desafiado várias instituições que buscam conciliar vida profissional e familiar dos seus servidores. A pesquisa busca identificar os impactos que ocorreram na qualidade de vida de servidores públicos, em especial servidores do Tribunal de Justiça do Estado do Amazonas, em arranjo de home office, modalidade contemporânea de realizar atividades laborais, sendo à distância da instituição e fazendo uso de tecnologias de informação e comunicação. Para tanto, foi aplicado um questionário on line do Google Forms a 57 teletrabalhadores da instituição, com perguntas fechadas, baseadas em uma perspectiva pragmática, os dados foram analisados a partir da estatística descritiva e os resultados demonstraram que existem ganhos na qualidade de vida do servidor em teletrabalho, impactando positivamente no seu desempenho profissional, ademais, o teletrabalho promove vantagens de economia de tempo e redução de custos nos deslocamentos até o trabalho e melhora a relação trabalho-família. Em suma, o trabalho remoto, antes de ser um aspecto a ser controlado, possa ser um elemento que favoreça o desenvolvimento psicossocial e organizacional, mediante a produção coletiva de novas formas de trabalho.

Palavras chave: Trabalho; Qualidade de Vida; Teletrabalho; Tecnologia.

\section{Telework verses Quality of Life: An Approach on Experiences Lived by Public Sever of the Amazonas State Court of Justice}

\begin{abstract}
The objective is to analyze the perception of people who perform part or all of their work at a distance from employing organizations, using technology media. Specifically, we seek to verify if there is an improvement in the satisfaction of the person who opts for remote work, as well as, advantages and disadvantages of remote work. The search for quality of life is a current theme and has challenged several institutions that seek to reconcile the professional and family life of their employees. The perception that the worker has regarding satisfaction with their working life, and the feeling of well-being about their daily life, impacts their performance. The research seeks to identify the impacts that occurred on the quality of life of public servants, especially servants of the Court of Justice of the State of Amazonas, after joining the home office, contemporary mode of performing their activities, being at a distance from the institution and making use of information and communication technologies. For this, an online questionnaire from Google Forms was applied to 57 teleworkers of the institution, with closed questions, based on a pragmatic perspective, the data were analyzed from descriptive statistics. The results showed that there are gains in the quality of life of the severs at the teleworking, thus impacting their professional performance. In addition, teleworking promotes time saving advantages and cost reduction in commuting to work and improves the work-family relationship. In short, remote work, before being an aspect to be controlled, can be an element that favors psychosocial and organizational development through the collective production of new forms of work.
\end{abstract}

UFAMBR, Manaus, v. 2, n. 3, art. 4, pp. 58-78, julho-dezembro, 2020 http://www.periodicos.ufam.edu.br/ufambr 
Teletrabalho versos Qualidade de Vida: uma Abordagem sobre as Experiências Vividas por Servidores do Tribunal de Justiça do Estado do Amazonas

Keywords: Work; Quality of Life; Telework; Technology.

\section{Teletrabajo versus Calidad de Vida: Una aproximación a las experiencias vividas por servidor público de la Corte de Justicia del Estado de Amazonas}

\section{Resumen}

El objetivo es analizar la percepción de las personas que realizan parte o la totalidad de su trabajo a distancia de las organizaciones empleadoras, utilizando medios tecnológicos. En concreto, buscamos comprobar si existe una mejora en la satisfacción de la persona que opta por el trabajo a distancia, así como, ventajas y desventajas del trabajo a distancia. La búsqueda de la calidad de vida es un tema actual y ha desafiado a varias instituciones que buscan conciliar la vida profesional y familiar de sus empleados. La percepción que tiene el trabajador sobre la satisfacción con su vida laboral y la sensación de bienestar en su vida diaria impacta en su desempeño. La investigación busca identificar los impactos que ocurrieron en la calidad de vida de los servidores públicos, en especial de los servidores de la Corte de Justicia del Estado de Amazonas, luego de incorporarse al Ministerio del Interior, modo contemporáneo de realizar sus actividades, al estar alejados de la institución y haciendo uso de las tecnologías de la información y la comunicación. Para ello, se aplicó un cuestionario online de Google Forms a 57 teletrabajadores de la institución, con preguntas cerradas, con base en una perspectiva pragmática, los datos fueron analizados a partir de estadística descriptiva. Los resultados mostraron que hay ganancias en la calidad de vida del servidor de teletrabajo, impactando así su desempeño profesional. Además, el teletrabajo promueve ventajas de ahorro de tiempo y reducción de costos en los desplazamientos al trabajo y mejora la relación trabajo-familia. En definitiva, el trabajo a distancia, antes de ser un aspecto a controlar, puede ser un elemento que favorezca el desarrollo psicosocial y organizativo a través de la producción colectiva de nuevas formas de trabajo.

Palabras clave: Trabalhos; Qualidade de vida; Teletrabalho; Tecnologia. 
Teletrabalho versos Qualidade de Vida: uma Abordagem sobre as Experiências Vividas por Servidores do Tribunal de Justiça do Estado do Amazonas

\section{INTRODUÇÃO}

A forma com que as tecnologias da informação e comunicação (TICs) têm penetrado na vida das pessoas, em seu meio familiar, social e profissional, é algo bastante perceptível. Olha-se para um lado e para o outro, e o que se vê são, cada vez mais, pessoas fazendo uso dessas TICs aliadas à internet. São celulares, computadores, tablets e outros. A vida se processando através de mídias de tecnologia. Segundo Castells (1999, p. 43) "[...] a tecnologia é a sociedade, e a sociedade não pode ser entendida, ou representada sem suas ferramentas tecnológicas."

Os relacionamentos se modificam à medida que é permitido que estas tecnologias façam parte de nossas vidas. Afinal, é a era da Informação e da Comunicação! Vive-se a plenitude do século XXI. Muitas mudanças ocorridas após o período industrial, o chão de fábrica passa a contar com novas máquinas e robôs, escritórios virtuais, pessoas buscando com mais intrepidez o conhecimento e a vida social tomando novos rumos.

Em meio as estas mudanças as relações de trabalho, também vão se moldando à luz das novas tecnologias. Novas maneiras de realizar as atividades surgem, dentre elas, e um pouco mais recente, o teletrabalho, que em sentido amplo, refere-se ao trabalho realizado à distância das organizações empregadoras, fazendo uso de mídias de tecnologia. Para Mello (1999, p.11) “[...] é a substituição parcial ou total das viagens diárias do trabalho por tecnologia de telecomunicações, possivelmente com o auxílio de computadores, e outros recursos de apoio."

Muitos são os motivos que levam empresas públicas ou privadas, assim como seus profissionais, a optarem por esta forma de realização de trabalho. Estudos vêm demonstrando que há ganhos de forma geral com a prática do teletrabalho, segundo Lima (2018, p.18), o teletrabalho avança como opção contemporânea que demonstra, pelo lado da sociedade, incluindo-se aí o trabalhador, melhoria na qualidade de vida, qualidade do trabalho, mobilidade urbana, redução da poluição ambiental, custos menores com transporte, entre outros e, por outro lado, considerando a perspectiva das instituições, ganhos de produtividade, maximização do uso de espaços físicos, ênfase na gestão por resultados e redução de custos organizacionais.

Este estudo se dispõe a responder, levando-se em conta a visão do servidor público, se há melhorias na satisfação e na qualidade de vida do teletrabalhador e se este pretende permanecer nesta modalidade de trabalho. Justifica-se a escolha do tema por dois motivos. O primeiro, sendo a autora servidora do Tribunal de Justiça do Amazonas (TJAM) e com a recente implantação do teletrabalho, despertou o interesse em saber como esta modalidade de trabalho vem impactando na qualidade de vida dos servidores remotos da instituição, quais melhorias têm ocorrido em suas vidas. O segundo motivo é que o teletrabalho, embora realidade em nossos dias, ainda é um assunto pouco disseminado, por conseguinte torna-se importante conhecer a visão de teletrabalhadores a respeito das mudanças relativas a sua vida profissional e familiar, em adição espera-se contribuir para o enriquecimento do tema, bem como na tomada de decisão a respeito de se adotar, ou não, esta forma de realização de trabalho em outras instituições.

Objetiva-se com este estudo analisar a percepção de pessoas que realizam a maior parte do seu trabalho à distância das organizações empregadoras, fazendo uso de mídias de tecnologia, em 
Teletrabalho versos Qualidade de Vida: uma Abordagem sobre as Experiências Vividas por Servidores do Tribunal de Justiça do Estado do Amazonas

relação aos ganhos ou perdas de qualidade de vida. Especificamente, busca-se verificar se há uma maior satisfação com o teletrabalho, bem como, identificar vantagens e desvantagens do trabalho remoto.

\section{REFERENCIAL TEÓRICO}

\subsection{Trabalho: sua evolução e características ao longo da história}

As formas de realização de trabalho vêm sofrendo grandes transformações ao longo dos anos, modificando sua natureza e conceitos. Na plenitude do século XXI, as transformações vivenciadas, segundo Lima (2018), são motivadas principalmente pelo "uso intensivo das tecnologias da informação e comunicação (TICs), a escassez de recursos, a busca de eficiência pelas organizações, a reconfiguração dos processos produtivos, o aumento da população mundial antagonicamente à redução na disponibilidade de empregos formais e a consequente intensificação da automação.” (Lima, 2018, p.24).

Para Freitas (2008) e Lima (2018), a história nos dá conta de grandes acontecimentos ocorridos que marcaram de forma impactante e decisiva todas as esferas da vida, seja no ponto de vista econômico ou social, modificando as relações pessoais e de trabalho.

O primeiro deles, que perdurou por milhares de anos, denominado, segundo Freitas (2008) de Revolução Agrícola, caracterizava-se pelo uso da terra como meio de produção, cuja produção era familiar ou comunitária para consumo local. Lima (2018) caracteriza esse período em suas formas de produção e trabalho, onde se predominava atividades artesãs, pastoreio e caça, tendo como principal finalidade a subsistência familiar e de atendimento a mercados restritos (parentes, vizinhos, patrões). A força de trabalho era constituída por camponeses e pequenos agricultores. "Exigia-se mais esforços físicos a intelectuais". (Lima, 2018, p.24).

Outro grande acontecimento se refere à Revolução Industrial, que durou cerca de 300 anos, podendo ainda ser dividida em duas fases, as quais compreendem os diversos momentos desde o início do avanço industrial, iniciado na Inglaterra no século XVIII. O período contemplou o surgimento das estradas de ferro e da máquina a vapor, inventada por James Watt ( $1^{\mathrm{a}}$ fase $)$, em seguida o desenvolvimento das indústrias químicas, elétrica, de petróleo, aço, e da linha de montagem ( $2^{\mathrm{a}}$ fase). $\mathrm{O}$ meio de produção passa a ser o maquinário, e a produção torna-se impessoal e destinada ao comércio. É a transição do modelo de trabalho agrícola para o fabril, onde grande parte dos trabalhadores, agora denominados operários, concentram-se nos espaços físicos das fábricas, e outros fazem parte da cúpula das organizações, os trabalhadores intelectuais. Nesta segunda fase iniciou-se uma série de estudos que objetivavam tornar as fábricas mais eficientes e produtivas com o intuito de aprimoramento da produção e obtenção de melhores resultados. Frederick Winslow Taylor, conhecido como o "pai da Administração", foi o precursor destes estudos (Lima, 2018, p. 25; Freitas, 2008, p.18).

Após este período onde foram introduzidos nas organizações os métodos de Taylor e de outros pensadores da ciência da Administração, os enfoques de estudos passaram a apontar para outros fatores de influência na produção, assim, as preocupações com a máquina e com os métodos dão lugar à inclusão do fator humano e as relações dos grupos sociais no ambiente de trabalho, sendo 
Teletrabalho versos Qualidade de Vida: uma Abordagem sobre as Experiências Vividas por Servidores do Tribunal de Justiça do Estado do Amazonas

o precursor destes estudos, Elton Mayo (1936), abordando as Teorias das Relações Humanas (Lima, 2018, p. 26).

A partir da segunda guerra mundial, a produção fabril, composta por bens materiais, dá vez à produção de bens não materiais, como inserção de serviços, informações, simbologias, estética e moda, classificando tal período como a era pós-industrial. (LIMA, 2018, p. 26 e 27).

O terceiro grande movimento que impactou e vem impactando as formas de realização de trabalho, é conhecido como a Revolução Informacional ou Digital, que tem seu início na década de 1960. Fatos importantes marcam este período, tais como: a inserção de semicondutores, a computação em mainframe (Década de 1960), o uso de computadores pessoais (Década de 1970 e 1980) e a explosão da internet (Década de 1990).

Schwab (2016), citado por Lima (2018, p. 27), refere-se ao período de transição da tecnologia analógica para a digital, de impactos globais, como "uma assombrosa profusão de novidades tecnológicas que abrange numerosas áreas", por meio da Inteligência Artificial (AI), robótica, Internet das coisas, veículos autônomos, impressão 3D e a explosão de aplicativos (apps), reconfigurando novas formas de trabalho e serviços.

Neste contexto o Teletrabalho é inserido, como uma nova possibilidade de se produzir trabalho, neste caso de forma remota, fazendo uso de ferramentas tecnológicas de informação e comunicação. E pode trazer vantagens como: à redução do tempo gasto em deslocamentos casatrabalho e combustíveis, flexibilidade de horário e ritmo de trabalho, permitindo conciliar vida profissional e familiar, flexibilização do local de trabalho, autonomia relativa, redução de gastos com alimentação e vestuário, possibilidade de emprego para pessoas que estavam à margem da força de trabalho (idosos, pessoas com necessidades especiais, responsáveis por crianças pequenas).

\subsection{Teletrabalho}

\subsubsection{Conceito e origens.}

O teletrabalho constitui tema relativamente recente, tanto como prática quanto na literatura administrativa, especialmente no Brasil. Surgiu como proposta nos anos 1970, como possível resposta à crise do petróleo, ao aumento dos problemas do trânsito nas grandes metrópoles e, ainda, no cenário de maior afluxo das mulheres ao mercado de trabalho. No entanto, é a partir dos anos 1990 que o tema ganha força, especialmente nos países do chamado Primeiro Mundo, em virtude das crescentes sofisticação e massificação das tecnologias de informática e telecomunicações (TICs).

Não há uma definição exata para conceituar teletrabalho, mas, em linhas gerais, refere-se ao trabalho realizado a distância das organizações empregadoras, fazendo uso de tecnologias de informação e comunicação, como computadores, celulares, smartphones e outros. Mello (1999), o descreve como sendo "[...]a substituição parcial ou total das viagens diárias do trabalho por 
Teletrabalho versos Qualidade de Vida: uma Abordagem sobre as Experiências Vividas por Servidores do Tribunal de Justiça do Estado do Amazonas

tecnologia de telecomunicações, possivelmente com o auxílio de computadores, e outros recursos de apoio" (Mello, 1999, p.11).

Para Goulart (2009), "é o processo de levar o trabalho aos empregados em vez de levar estes ao trabalho; atividade periódica fora da empresa um ou mais dias por semana, seja em casa, seja em outra área intermediária de trabalho". (Goulart, 2009, p.25).

Costa (2004), citado por Lima (2018), sintetiza variadas definições de diversos autores sobre o tema teletrabalho, descrevendo-o como sendo "a forma de trabalho realizado a distância, remotamente e viabilizado pelos recursos das Tecnologias da Informação e Comunicação (TICs), predominando o local de sua realização no domicílio dos teletrabalhadores ou chamados home office." (Lima, 2018, p. 20).

Teletrabalho, deriva do termo em inglês "telecommuting", e ainda: home working (trabalho em casa), home office (escritório em casa), telework ou teleworking (trabalho a distância), working from home (trabalho para casa), mobile work (trabalho móvel), remote work (trabalho remoto) e flexible workplace (local de trabalho flexível).

De acordo com Kugelmass (1995), citado por Ferreira Júnior (2000, p.9), “o trabalho remoto, ou o gerenciamento a distância, foi inventado em 1857 por J. Edgar Thompson, da empresa Penn Railroad, quando ele descobriu que poderia usar o sistema privado de telegrafia da empresa para controlar o uso dos equipamentos do laboratório". A empresa usava o sistema privado de telégrafo para gerenciar seus funcionários, que estariam longe fisicamente do escritório central (Lima, 2018, p.29).

O termo teletrabalho é relativamente novo e pouco disseminado na sociedade. Os primeiros estudos datam da década de 1970, quando o físico americano Jack Nilles, considerado o "pai do teletrabalho", dirigiu o primeiro deles nomeando a experiência de telecommuting, referindo-se à possibilidade de eliminar o trajeto de casa ao trabalho. (Lima, 2018, p. 30). Era o resultado de "uma investigação prática sobre a substituição dos transportes pela telecomunicação. Com a crise do petróleo, soluções que reduzissem seu consumo eram amplamente pesquisadas." (Freitas, 2008, p. 33).

O teletrabalho não é uma tendência, mas, pelo contrário, uma realidade cada vez mais presente nos países desenvolvidos, ganhando espaço em diferentes tipos de empresas, sejam elas públicas ou privadas.

\subsubsection{Vantagens e desvantagens, perfil profissional.}

Embora estudos venham demonstrando que há ganhos e benefícios com a prática do teletrabalho, pontos importantes devem ser considerados no momento de decidir por esta modalidade de trabalho, pois envolvem questões de fundo econômico, social e psicológico.

Silva (2004, p. 36-40) e Freitas (2008, p. 39-41) apontam às principais vantagens e desvantagens, que envolvem o trabalho remoto para o trabalhador, a empresa e a sociedade. As vantagens

UFAMBR, Manaus, v. 2, n. 3, art. 4, pp. 58-78, julho-dezembro, 2020 http://www.periodicos.ufam.edu.br/ufambr 
Teletrabalho versos Qualidade de Vida: uma Abordagem sobre as Experiências Vividas por Servidores do Tribunal de Justiça do Estado do Amazonas

apontadas para o trabalhador se referem à redução do tempo gasto em deslocamentos casatrabalho e combustíveis, aumento da produtividade com menos distrações, flexibilidade de horário e ritmo de trabalho, permitindo conciliar vida profissional e familiar, flexibilização do local de trabalho, autonomia relativa, redução de gastos com alimentação e vestuário, possibilidade de emprego para pessoas que estavam à margem do mercado de trabalho (idosos, pessoas com necessidades especiais, responsáveis por crianças pequenas). Quanto às desvantagens, os autores apontam o isolamento social, a redução do contato com colegas, modificação significativa nas relações em que um indivíduo está inserido, aumento dos custos pessoais com o trabalho (quando a empresa não arcar com os mesmos), alguns casos podem gerar problemas na vida familiar devido à intromissão do trabalho no lar, problemas de proteção jurídica em casos que o trabalho remoto não estiver devidamente regulamentado, menos oportunidades de promoção.

No que concerne às empresas as vantagens se dão por meio de redução de custos (imobiliários, de transportes, de pessoal), redução do absenteísmo, aumento da produtividade, operação a nível global e funcionamento 24 horas, em casos de catástrofes (enchentes, furacões, epidemias) que não causem paralizações nas telecomunicações, as atividades dos teletrabalhadores não são interrompidas, facilidades no recrutamento de pessoal, podendo ser realizado independentemente do local de residência. Quanto às desvantagens, os autores citam as dificuldades em estabelecer critérios de produtividade, uma vez que o trabalho passa a ser medido em termos de resultados ou por tarefas, problemas com segurança de dados, aumento dos custos com formação do trabalhador, aumento com custos de equipamentos extras, energia e telecomunicações (no caso de serem arcados pelo empregador), ausência de leis que definam o funcionamento do teletrabalho. Esta última, com a maior abrangência do teletrabalho, vem sendo resolvida.

Para a sociedade as vantagens se dão com a 'desconcentração' dos centros urbanos, com eventual diminuição de congestionamentos, redução da poluição ambiental, economia em combustíveis, revitalização dos subúrbios, criação de novos empregos, proporcionando, principalmente a integração ao mercado de trabalho de pessoas com necessidades especiais, idosos, donas de casa etc. Como desvantagem, os autores salientam para os efeitos negativos na integração social do trabalhador na comunidade (trabalho e residência).

Observando-se as vantagens, bem como as desvantagens de um profissional que atua de forma remota, percebe-se que os desafios são enormes quando se opta por este "estilo" de realização de trabalho. Algumas características devem estar presentes nestes profissionais, sob o risco até de não dar certo o desenvolvimento de suas atividades.

Goulart (2009) aponta alguns atributos importantes para um teletrabalhador, dos quais podemos destacar:

$\checkmark$ Automotivação - demonstração de interesse e entusiasmo contagiantes;

$\checkmark$ Adaptabilidade - capacidade de ajustar-se a qualquer ambiente sem problemas.

$\checkmark$ Autodisciplina - capacidade de controlar-se a si próprio;

$\checkmark$ Confiança - crer nas próprias qualidades e potencialidades;

$\checkmark$ Flexibilidade - Adequar-se às novas circunstâncias e novos conhecimentos;

$\checkmark$ Independência - Capacidade de tomar decisões por conta própria, responsavelmente;

UFAMBR, Manaus, v. 2, n. 3, art. 4, pp. 58-78, julho-dezembro, 2020 http://www.periodicos.ufam.edu.br/ufambr 
Teletrabalho versos Qualidade de Vida: uma Abordagem sobre as Experiências Vividas por Servidores do Tribunal de Justiça do Estado do Amazonas

Confiabilidade - capacidade de despertar a confiança de outrem em suas colocações e atitudes.

\subsection{O teletrabalho na gestão pública brasileira: aspectos relevantes do Poder Judiciário no âmbito nacional e amazonense}

A reforma gerencial do Estado brasileiro, iniciada em 1995, veio ao encontro das necessidades de mudanças na forma de administrar as organizações públicas no Brasil, haja vista o crescimento das funções econômicas e sociais do Estado, o impacto gerado pelo desenvolvimento tecnológico e os efeitos da globalização. Os objetivos propostos pela reforma dão vistas à descentralização de uma estrutura organizacional ultrapassada, burocrática, para um modelo de gestão por resultados e por excelência, buscando mudanças na mentalidade dos gestores no trato da coisa pública com maior objetividade e profissionalismo. (Bressser-Pereira, 2009, citado por Lima, 2018, p.42).

Neste cenário de buscas constantes por melhores resultados, otimizando-se recursos e com o aumento crescente do uso de TICs, que no início do século XXI surge o teletrabalho, uma nova ferramenta de gestão para obtenção de melhores resultados para a Administração Pública. (Lima, 2018, p.42)

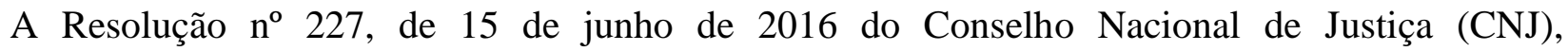
regulamentou o teletrabalho no âmbito do judiciário nacional, permitindo aos tribunais brasileiros a adoção do programa. Alguns órgãos do judiciário já vinham praticando o teletrabalho e suas experiências serviram como fontes para elaboração da referida resolução (Lima, 2018, p. 43).

$\mathrm{O}$ artigo terceiro deste regramento judiciário enumera os objetivos a serem alcançados com a prática do teletrabalho, no que diz respeito a servidores, tribunais e sociedade. Conforme Lima (2018), para os servidores "considerou-se a possibilidade de promover [...] um mecanismo para atraí-los, motivá-los e comprometê-los com os objetivos da instituição". Assim, o teletrabalho promove vantagens de economia de tempo e redução de custos nos deslocamentos até o trabalho, aumenta as possibilidades de trabalho aos servidores com dificuldade de locomoção, bem como promove melhorias de qualidade de vida e respeito as diversidades. (Lima, 2018, p. 45).

Para os tribunais o teletrabalho objetiva o aumento da produtividade e da qualidade de trabalho dos servidores, promove a cultura orientada a resultados, estimula o desenvolvimento de talentos, criatividade e a inovação. Ademais, deve-se considerar com o teletrabalho, a multiplicidade das tarefas, dos contextos de produção e das condições de trabalho para a concepção e implemento de mecanismos de avaliação e alocação de recursos. (Lima, 2018, p.45 e CNJ, 2016).

Para a sociedade, o teletrabalho contribui "para a melhoria de programas socioambientais, com a diminuição de poluentes e a redução no consumo de água, esgoto, energia elétrica, papel e de outros bens e serviços disponibilizados nos órgãos do Poder Judiciário" (CNJ, 2016).

No que tange ao Poder Judiciário amazonense, a regularização do teletrabalho veio através da publicação da Resolução $n^{\circ}$ 04/2017, de 16 de maio de 2017. A referida resolução trata o teletrabalho como "modalidade de trabalho realizado de forma remota, em local adequado às 
Teletrabalho versos Qualidade de Vida: uma Abordagem sobre as Experiências Vividas por Servidores do Tribunal de Justiça do Estado do Amazonas

condições de privacidade e de segurança exigidas pelo serviço, mediante a utilização de tecnologias de informação e de comunicação". (TJAM, 2017). O programa se baseia no modelo home office (na casa do servidor) e as atividades laborais são desenvolvidas em horário completamente flexível. (Lima, 2018, p. 93).

O programa tem como perspectiva a redução de gastos públicos com eletricidade, papel e outros insumos arcados pelo serviço público; geração de benefícios ao meio ambiente, em consequência da redução do fluxo de veículos e consequente diminuição da emissão de poluentes, além de favorecimento da qualidade de vida dos servidores (TJAM, 2019).

Um ponto importante que trata a Resolução $\mathrm{n}^{\circ}$ 04/2017, artigo $8^{\circ}$, inciso VII, é a vedação de realização do trabalho remoto a servidores que estejam fora do país, salvo na hipótese de servidores que tenham direito à licença para acompanhar o cônjuge. Entretanto, recentemente, com a publicação da Resolução $\mathrm{n}^{\circ}$ 08/2019, de 16 de abril de 2019, o referido artigo foi revogado, permitindo-se assim, que o teletrabalhador desempenhe suas atividades laborais em qualquer lugar do mundo que se encontre. (TJAM, 2019).

Atualmente, o Poder Judiciário Estadual conta com 57 servidores em sistema de teletrabalho, com perspectiva de ampliar para 100 servidores até o final de 2019. (TJAM, 2019).

O Tribunal de Justiça do Amazonas (TJAM) foi anunciado, pelo Conselho Nacional de Justiça (CNJ), como a instituição vencedora do $1^{\circ}$ Prêmio de Práticas em Gestão de Pessoas do Poder Judiciário, sendo o único dentre os Tribunais Estaduais a receber destaque nacional conquistando, com seu Programa de Teletrabalho, a primeira colocação no prêmio, na categoria "Planejamento em Gestão de Pessoas". Para o atual presidente do TJAM, Desembargador Yedo Simões de Oliveira, a premiação inédita concedida ao Judiciário Estadual é de grande significância e aponta para a efetividade das ações de inovação postas em prática pela Corte. Conforme as palavras do Presidente, "o reconhecimento público ao programa de teletrabalho só seria possível com o devido investimento que temos realizado em nossos sistemas de automação judicial e tramitação processual, que são hoje 100\% virtuais [...]". (TJAM, 2019).

\subsection{Qualidade de vida do Teletrabalhador}

A busca pela qualidade de vida é um tema bastante discutido atualmente. Mas definir o que vem a ser qualidade de vida não é tão simples, pois tem a ver com a percepção de um indivíduo em relação à satisfação com sua vida cotidiana, o seu bem-estar dentro da sociedade.

De acordo com a Organização Mundial de Saúde (OMS), qualidade de vida é a "percepção do indivíduo de sua inserção na vida, no contexto da cultura e sistemas de valores nos quais ele vive e em relação aos seus objetivos, expectativas, padrões e preocupações”. (BVS, 2013).

$\mathrm{O}$ conceito de qualidade de vida está diretamente associado à autoestima e ao bem-estar pessoal e compreende vários aspectos, como a capacidade funcional, o nível socioeconômico, o estado emocional, a interação social, o suporte familiar, a saúde, valores culturais, éticos e religiosos, o 
Teletrabalho versos Qualidade de Vida: uma Abordagem sobre as Experiências Vividas por Servidores do Tribunal de Justiça do Estado do Amazonas

estilo de vida, a satisfação com o trabalho, e com o ambiente em que se vive. (Vecchia et al, 2005, p. 246).

Gil Gordon, conhecido em vários países como um dos mais credenciados consultores na implantação do teletrabalho, esclarece que são muitos os benefícios e melhorias na qualidade de vida de um teletrabalhador. O simples fato de poder trabalhar sem ter que se vestir formalmente, não necessitar enfrentar o trânsito diariamente, poder conciliar a vida pessoal e a profissional mais facilmente, estar em casa quando as crianças chegarem da escola, até mesmo colocar a roupa na máquina de lavar ao invés de deixar a pilha se acumular esperando o fim de semana, proporciona menos estresse e mais tempo para o lazer. (Mello, 1999, p. 36 e 54).

Conforme relata um servidor do Tribunal de Justiça do Estado do Amazonas, diagnosticado com cinco hérnias de disco, enfrentando crises agudas ao se locomover ao local de trabalho e permanecer sentado por muitas horas: "não conseguia dirigir de forma confortável e, no dia a dia de trabalho, ao passar muito tempo sentado, enfrentava muitas crises por conta do grave problema na coluna. Hoje, com o teletrabalho, minha vida mudou completamente e consigo desempenhar minhas atividades, adotando uma rotina que inicia às $7 \mathrm{~h}$ da manhã, deixando minha filha na escola; fazendo em seguida os exercícios físicos próprios do tratamento para a coluna; iniciando as atividades judiciais home office às $8 \mathrm{~h}$, que prosseguem até às $14 \mathrm{~h}$, com um intervalo às $12 \mathrm{~h}$ e dando atenção às atividades (do trabalho) que exigem maior concentração, à noite. Sou agradecido a esta oportunidade e posso dizer que a nova rotina tem mudado minha vida para melhor" (TJAM, 2019). O teletrabalho realizado na residência do servidor pode ter um impacto na segurança e saúde no trabalho (SST) dos teletrabalhadores positivamente.

Todavia, os empregadores têm as mesmas responsabilidades com os teletrabalhadores que têm com quaisquer outros trabalhadores. Estes incluem a identificação e gestão dos riscos ocupacionais dos teletrabalhadores nas suas residências. Um ambiente de trabalho na residência adequado deve incluir:

$\checkmark \mathrm{U}$ m espaço em que o teletrabalhador pode trabalhar;

$\checkmark$ Permite ao teletrabalhador estar acústica e visualmente isolado, facilitando a concentração e minimizando distrações;

$\checkmark$ Contribui para manter uma fronteira entre as vidas laboral e familiar. Uma forma simbólica de estabelecer a divisão entre estas duas esferas;

$\checkmark$ Temperatura, unidade e ventilação adequadas;

$\checkmark$ Iluminação adequada (incluindo luz natural) para desempenhas as tarefas com eficácia, precisão e de modo saudável;

$\checkmark$ Ligação à internet e linha telefônica adequada (se necessário);

$\checkmark$ Verificação periódica de falhas no equipamento e na instalação elétrica.

Outro servidor do quadro do TJAM solicitou exoneração do cargo, em virtude de dificuldades de acessibilidade arquitetônica, nos mobiliários e equipamentos, nos transportes, na comunicação, dentre outros. Sendo usuário de cadeira de rodas e com certos problemas de saúde, a forma atual de organização do trabalho o impedia de continuar desenvolvendo suas atividades laborais. Após recomendação médica solicitou seu desligamento do cargo público, mesmo sendo considerado 
Teletrabalho versos Qualidade de Vida: uma Abordagem sobre as Experiências Vividas por Servidores do Tribunal de Justiça do Estado do Amazonas

por muitos um excelente profissional, com produtividade elevada e colaborativo com colegas e superiores.

A Divisão de Gestão de Pessoas tomando conhecimento do caso e com a anuência da chefia do servidor, entrou em contato e informou sobre o programa de teletrabalho do órgão. O servidor avaliou a possibilidade e ingressou no referido programa. Por conseguinte, a adesão ao programa foi autorizado pela presidência do órgão, levando-se em consideração a peculiaridade que o caso requeria. Desta forma, foi garantindo o pleno desenvolvimento do servidor, o exercício da cidadania e o acesso ao trabalho.

\section{METODOLOGIA}

Atuando na modalidade de trabalho remoto, no âmbito do Tribunal de Justiça do Estado do Amazonas, existem 57 servidores, entre homens e mulheres, e todos participaram deste estudo. Destaca-se que o TJAM, através da Resolução nº 04/2017, regulamenta e apresenta todas as etapas que o servidor interessado em ingressar no teletrabalho deverá submeter-se, entre elas: estar estável no serviço público, ter anuência do superior hierárquico, participar de treinamento específico voltado à otimização do serviço prestado remotamente e neste período deverá receber orientações quanto à saúde psíquica e ergonomia. Ademais, a produtividade do teletrabalhador deverá ser superior à produtividade dos servidores que executam a mesma atividade nas dependências do órgão.

A justificativa da escolha dessa população deve-se a certos fatores e a eles importa referir: todos os participantes desenvolvem suas atividades diárias na modalidade remota, e estão a mais de seis meses atuando desta forma e são servidores estáveis no serviço público ou, ainda, servidores exclusivamente comissionados (cumprida às exigências legais contidas na Resolução $\mathrm{n}^{\circ}$ 04/2017).

Para esta pesquisa, inicialmente, foram desenvolvidas as revisões e pesquisas bibliográficas necessárias para melhor compreender o objeto de estudo, pesquisou-se em materiais com dados já elaborados e publicados por meio escrito e/ou eletrônico, constituídos principalmente de livros, pesquisas, artigos científicos e páginas na web, onde se acredita poder cobrir uma gama de fatos muito mais ampla do que aquela que poderia investigar mediante observação direta. Em seguida, solicitou-se oficialmente à direção do Tribunal de Justiça do Amazonas autorização para aplicação da pesquisa.

A fim de se aproximar da realidade pesquisada, foi desenvolvida uma pesquisa quantitativa, a partir da composição de um questionário on line do Google Forms, com perguntas fechadas, auto administradas, baseadas em uma perspectiva pragmática. O questionário foi direcionado a todos os trabalhadores remotos do TJAM, através de envio de um link da internet para o e-mail institucional.

Após a pesquisadora enviar o questionário a todos os servidores, 24 instrumentos de pesquisa retornaram preenchidos de forma adequada, representando $42 \%$ dos servidores em trabalho remoto. Os dados foram analisados a partir da estatística descritiva. Os servidores remotos foram 
Teletrabalho versos Qualidade de Vida: uma Abordagem sobre as Experiências Vividas por Servidores do Tribunal de Justiça do Estado do Amazonas

convidados a responderem a perguntas acerca de temáticas relevantes no que concerne à qualidade de vida após o ingresso no teletrabalho. Os temas abordados trataram sobre as relações familiares e profissionais desenvolvidas no mesmo espaço físico, convívio familiar e social, motivação para atividades extra laboral, saúde física e emocional, integração com a equipe de trabalho, isolamento social, permanência no regime de teletrabalho, expectativas e satisfação com o teletrabalho.

\section{RESULTADOS OBTIDOS}

\subsection{Análise dos Resultados}

O total de respondentes da pesquisa correspondeu a 54,2\% do gênero feminino e $45,8 \%$ do gênero masculino, sendo que 54,2\% pertencem à faixa etária que vai dos 36 anos aos 49 anos, $41,7 \%$ pertencem à faixa etária de 21 a 35 anos e 4,2\%, tem idade igual ou superior a 50 anos. Todos pertencentes ao quadro de servidores do Tribunal de Justiça do Estado do Amazonas.

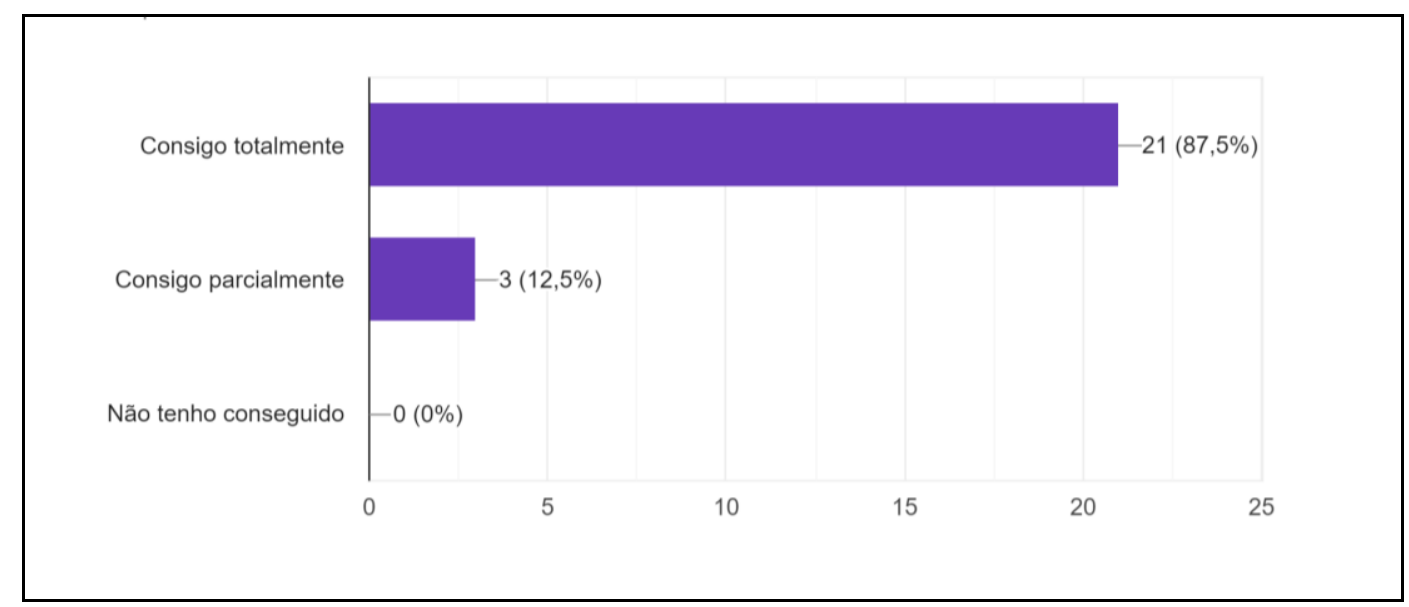

Gráfico 1: Relações familiares e profissionais no mesmo espaço físico.

O gráfico 1, aponta que 87,5\% dos profissionais da instituição que se encontram em regime de teletrabalho conseguem administrar totalmente as relações familiares e profissionais no mesmo espaço físico e 12,5\% conseguem administrar parcialmente. Em vista disso, equilibrar e contrabalancear as exigências do trabalho profissional e da família torna-se crucial para todos os membros da família e para um cotidiano mais gratificante. 
Teletrabalho versos Qualidade de Vida: uma Abordagem sobre as Experiências Vividas por Servidores do Tribunal de Justiça do Estado do Amazonas

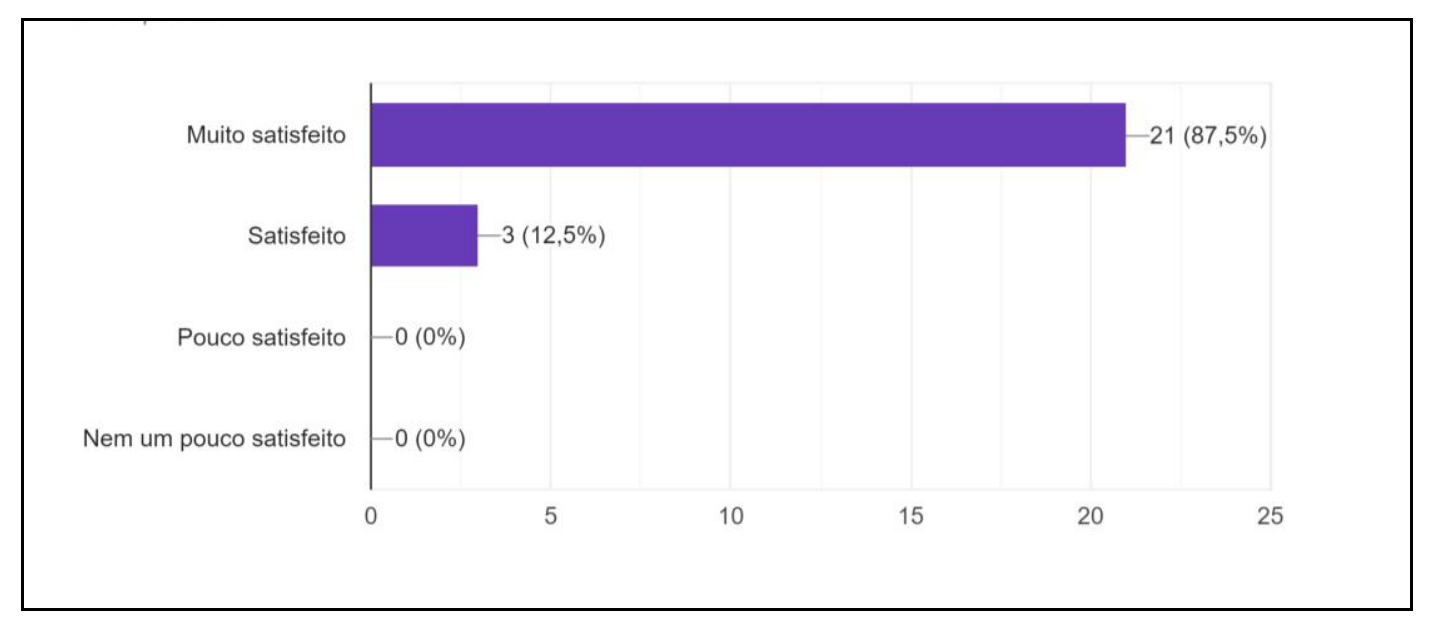

Gráfico 2: Convívio familiar

No gráfico 2, 87,5\% dos servidores participantes estão muito satisfeitos com a possibilidade de passar um tempo a mais com os seus familiares, resultado de terem ingressado no teletrabalho, enquanto $12,5 \%$ estão satisfeitos. Não obstante as sutilezas das relações trabalho-família, existem algumas evidências de investigação de que, em geral, aplicar medidas favoráveis à família acabou tornando-se uma situação vantajosa para ambas as partes, empregados e empresas, porque, além dos efeitos positivos para os pais que trabalham, acontece uma maior dedicação ao emprego e aumenta a produtividade dos pais empregados que recompensam as empresas pela aplicação de políticas orientadas à família (Kramer et al., 2008).

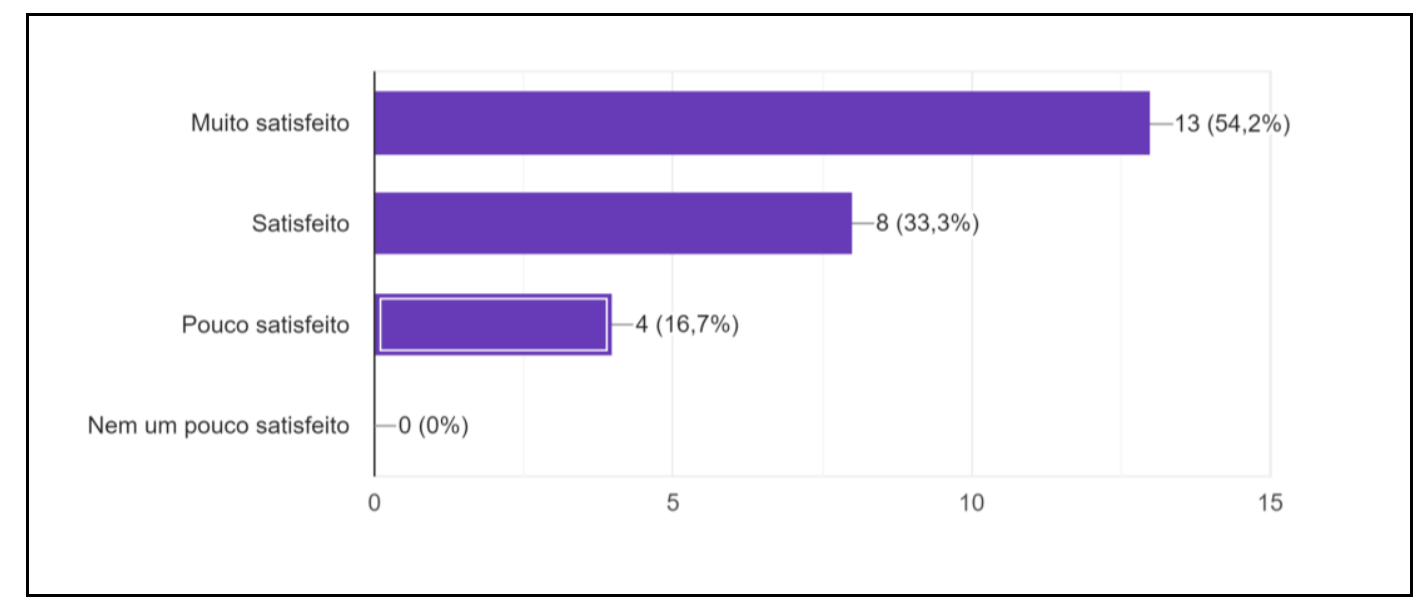

Gráfico 3: Convívio social.

O gráfico 3 indica que 54,2\% dos servidores respondentes estão muito satisfeitos em relação ao convívio social após terem ingressado no teletrabalho. Os resultados indicam também que 33,3\% estão satisfeitos e $16,7 \%$ se sentem pouco satisfeitos com o convívio social. 
Teletrabalho versos Qualidade de Vida: uma Abordagem sobre as Experiências Vividas por Servidores do Tribunal de Justiça do Estado do Amazonas

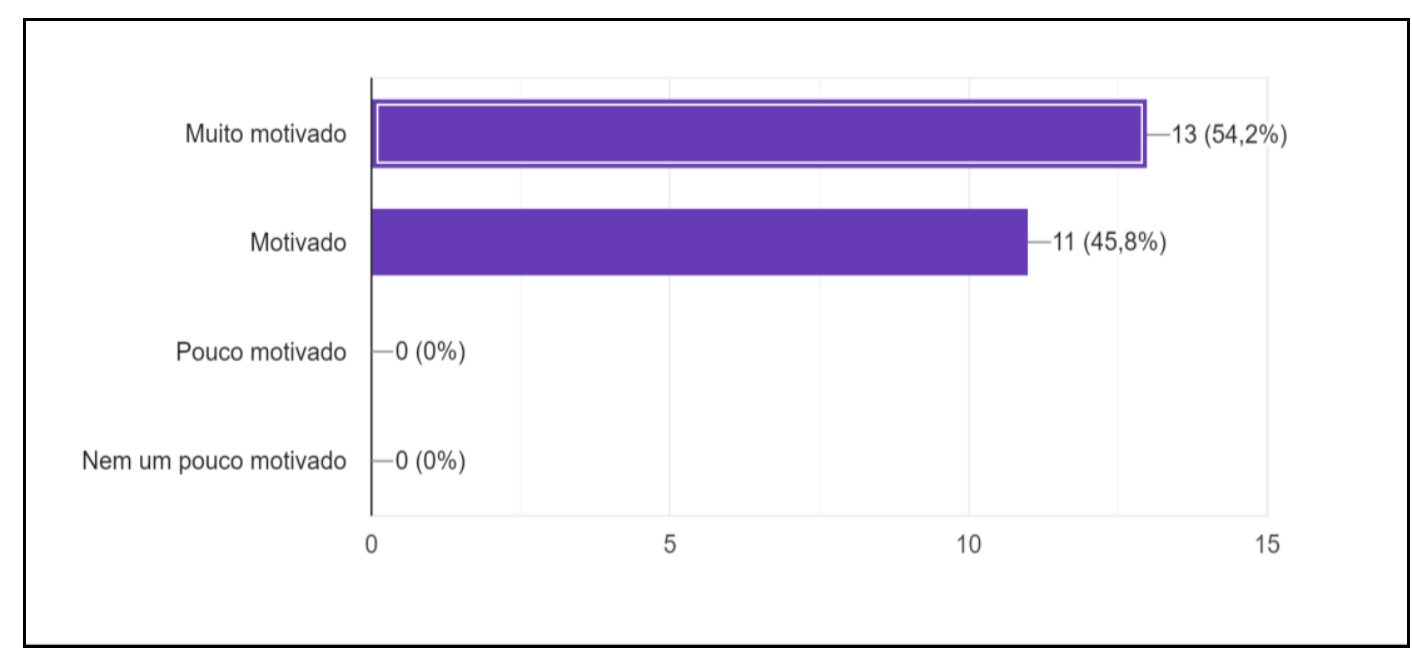

Gráfico 4: Motivação para atividades extra laboral

O gráfico 4 demonstra que 54,2\% dos respondentes se sentem muito motivados, após o ingresso no teletrabalho, a desenvolverem atividades extra laboral, como atividades físicas, novos estudos ou até mesmo aprender um novo idioma. Enquanto 45,8\% se sentem motivados.

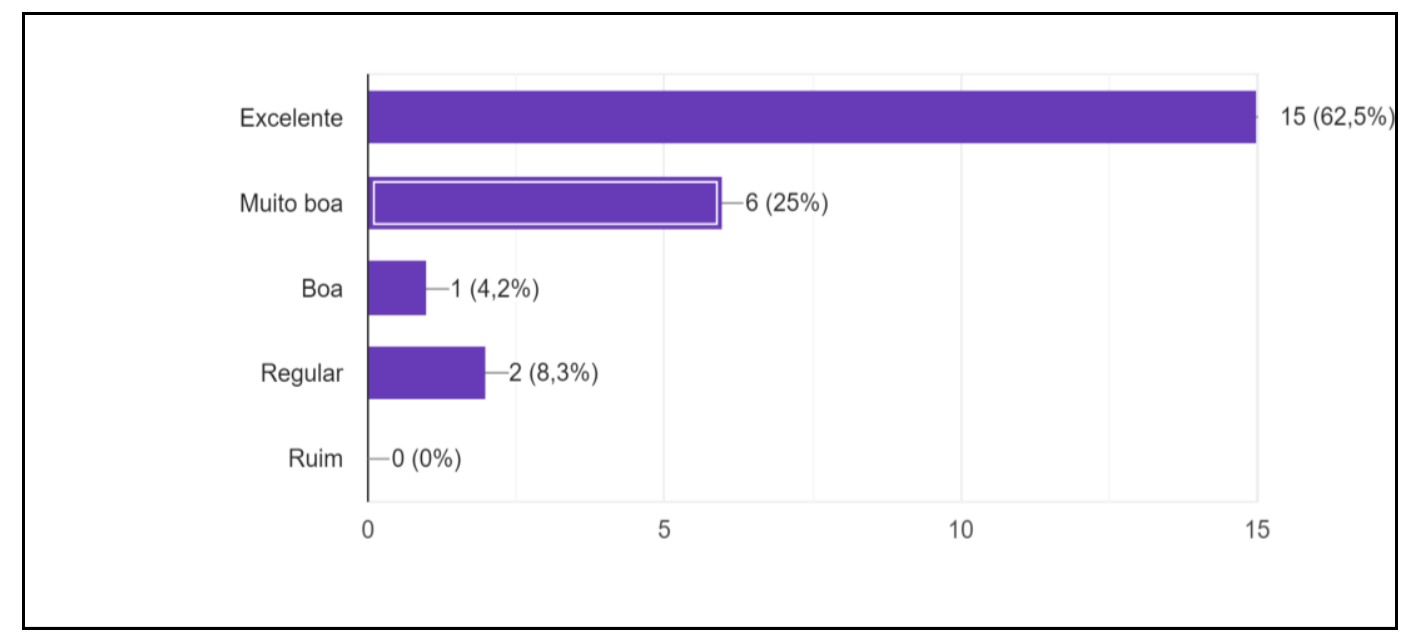

Gráfico 5: Saúde física e emocional.

A análise do gráfico 5 indica que 62,5\% dos respondentes classificam como excelente sua saúde física e emocional após o ingresso no teletrabalho, enquanto os demais a classificam como muito boa $(25 \%)$, boa $(4,2 \%)$ e regular $(8,3 \%)$. Sabe-se, hoje, que tanto o trabalho, quanto a atividade física e a diversão devem ter proporções satisfatórias a fim de propiciar um funcionamento psíquico saudável. (Guimarães, 2009) 
Teletrabalho versos Qualidade de Vida: uma Abordagem sobre as Experiências Vividas por Servidores do Tribunal de Justiça do Estado do Amazonas

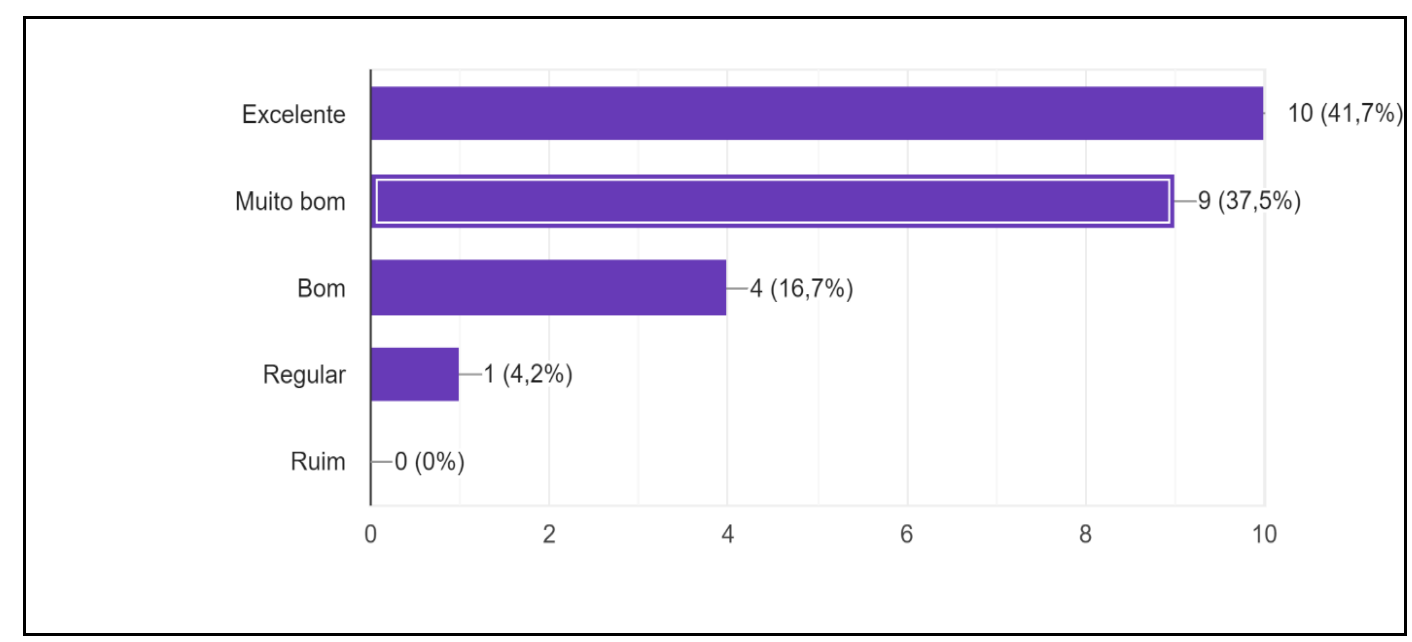

Gráfico 6: Integração com a equipe de trabalho.

O gráfico 6 demonstra que 41,7\% dos respondentes classificam a integração com a equipe de trabalho (gestores e colegas) como sendo excelente. Os demais a classificam como muito boa $(37,5 \%)$, boa $(16,7 \%)$ e regular $(4,2 \%)$.

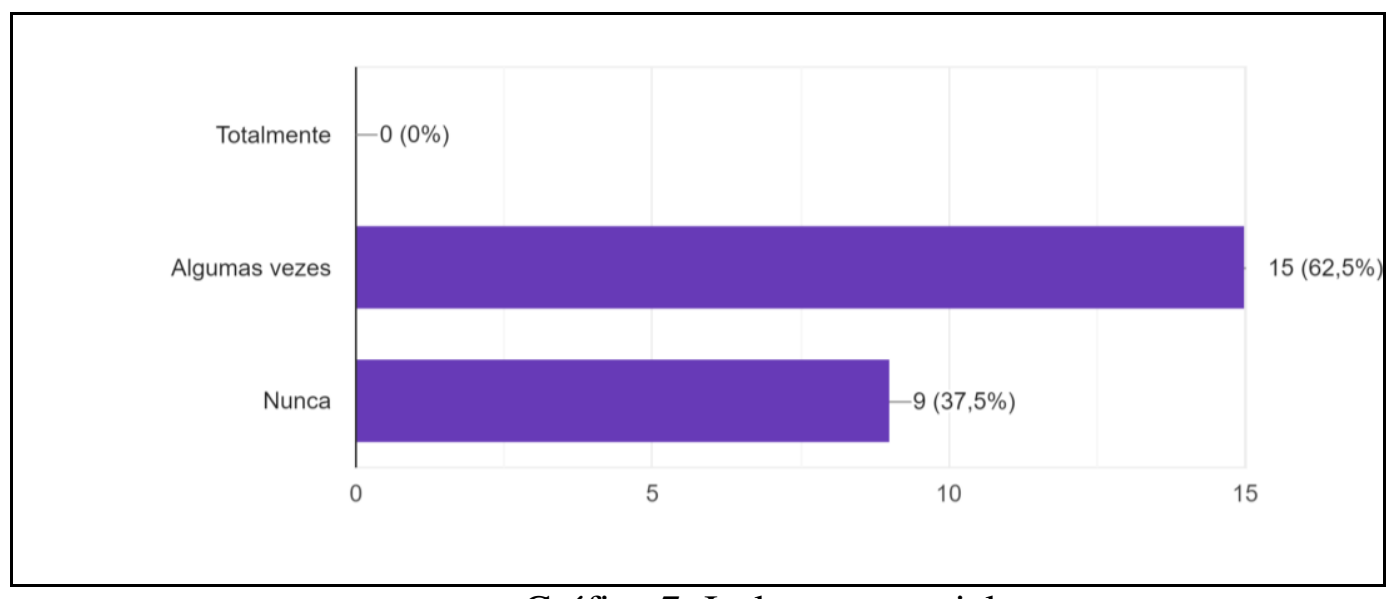

Gráfico 7: Isolamento social.

$\mathrm{Na}$ análise do gráfico 7, 62,5\% dos respondentes se sentem, algumas vezes, sozinhos ou isolados durante a realização das tarefas na modalidade remota e os demais, ou seja, 37,5\% responderam que nunca se sentem sozinhos ou isolados ao executar suas atividades estando em teletrabalho. Essas mudanças implicam reajustamentos psicossociais que pressionam para 'adaptações', as quais devem ser acompanhadas por profissionais da área da saúde mental no trabalho. 
Teletrabalho versos Qualidade de Vida: uma Abordagem sobre as Experiências Vividas por Servidores do Tribunal de Justiça do Estado do Amazonas

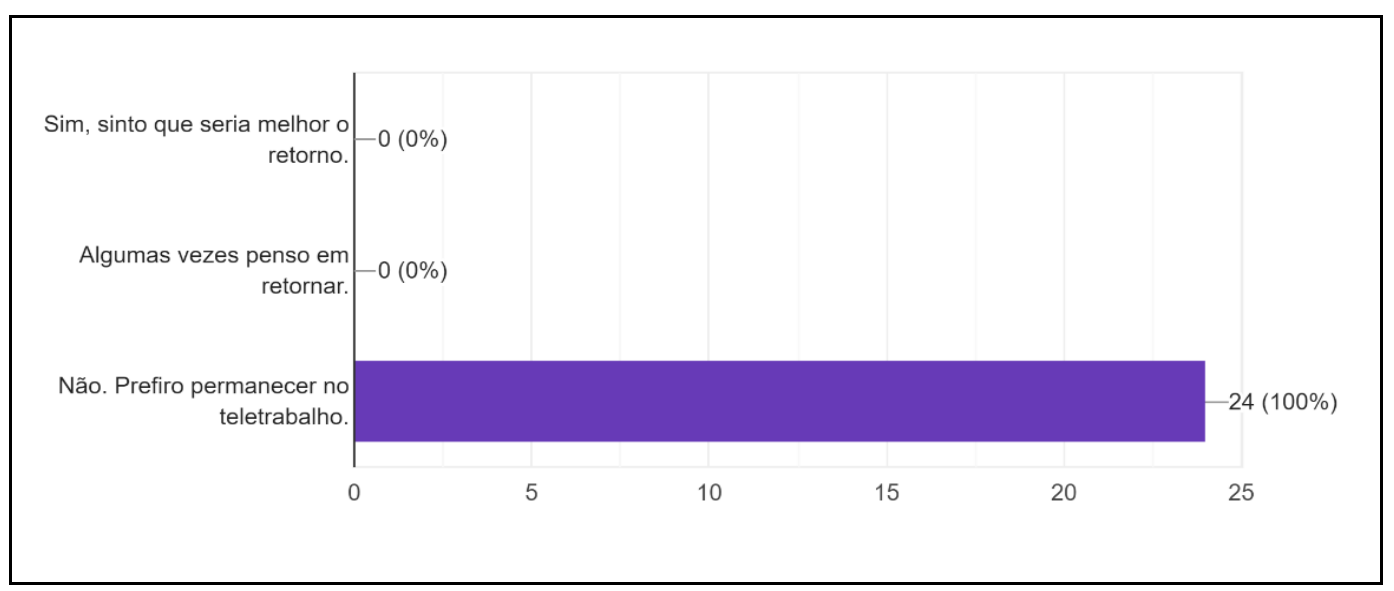

Gráfico 8: Permanência no regime de teletrabalho.

No gráfico $8,100 \%$ dos servidores que responderam à pesquisa preferem permanecer no regime de teletrabalho do que retornar ao trabalho convencional em seu órgão.

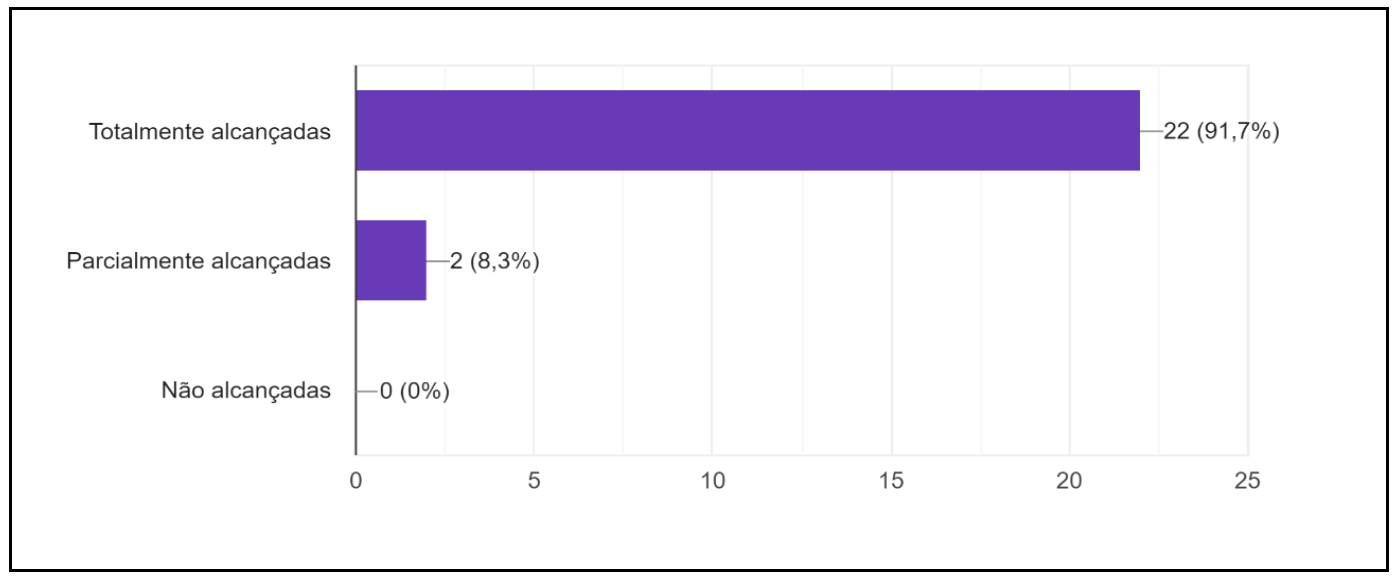

Gráfico 9: Expectativas com o teletrabalho.

O gráfico 9 indica que $91,7 \%$ dos servidores que responderam o instrumento de pesquisa tiveram suas expectativas totalmente alcançadas com o trabalho home office, sendo a minoria, ou seja, $8,3 \%$ responderam que alcançaram de maneira parcial suas expectativas com a nova modalidade de trabalho. Torna-se importante enfatizar que neste século, é fundamental desenvolver outras formas de estruturação do trabalho, além de ser imprescindível uma autocrítica da área de gestão de pessoas no que se refere ao bem-estar do ser humano no trabalho. (Guimarães, 2009) 
Teletrabalho versos Qualidade de Vida: uma Abordagem sobre as Experiências Vividas por Servidores do Tribunal de Justiça do Estado do Amazonas

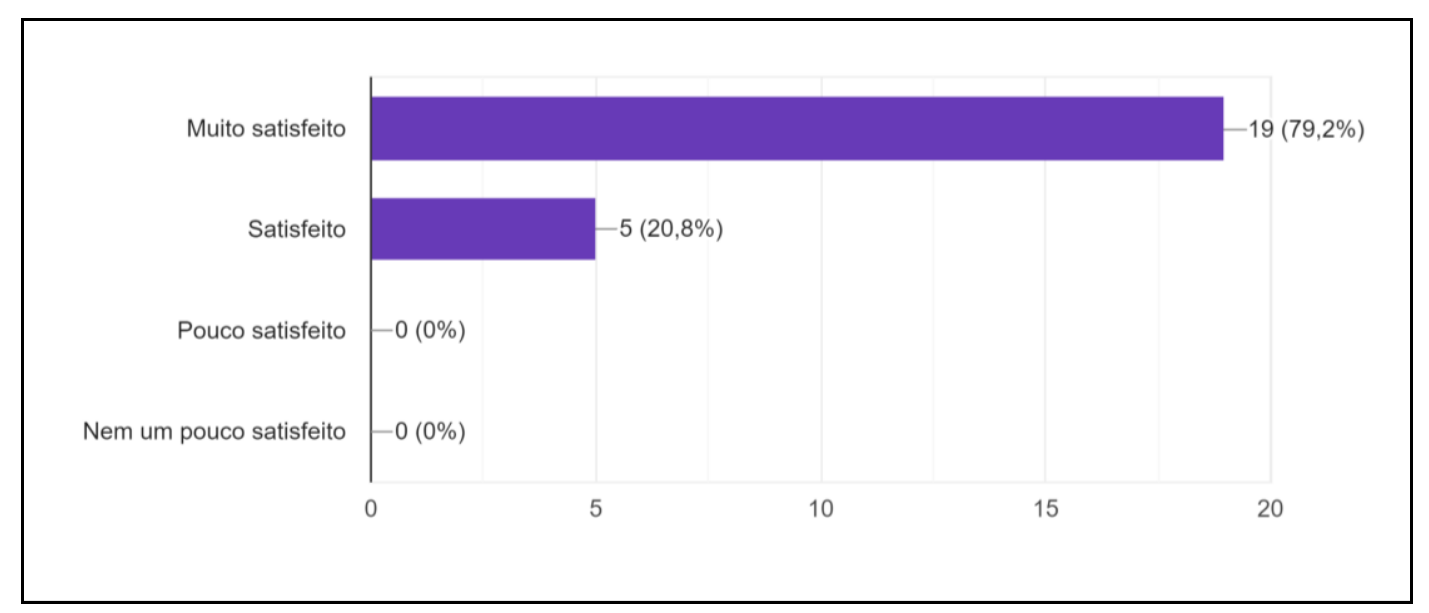

Gráfico 10: Satisfação com o teletrabalho.

O gráfico 10, aponta que a grande maioria, 79,2\% dos respondentes, se consideram muito satisfeitos com o teletrabalho e os demais, 20,8\%, se consideram satisfeitos de estarem trabalhando remotamente em suas residências. Frederick Herzberg, na década de 60, focalizou a questão da satisfação para formular sua teoria. Segundo ele, existem dois fatores que explicam o comportamento das pessoas no trabalho: os higiênicos e os motivacionais. Os fatores higiênicos localizam-se num ambiente de trabalho. São extrínsecos às pessoas e geram sentimentos de conformidade e acomodação positiva. Nessa categoria estão elencados: salário, benefícios sociais, condições físicas de trabalho, flexibilidade de horário, modelo de gestão, o que corrobora com os resultados encontrados.

\section{CONSIDERAÇÕES FINAIS}

O estudo teve como objetivo analisar a percepção de pessoas que realizam a maior parte do seu trabalho à distância das organizações empregadoras, fazendo uso de mídias de tecnologia em relação aos ganhos ou perdas de qualidade de vida. Buscou-se verificar se há melhorias na qualidade de vida do teletrabalhador, bem como, identificar vantagens e desvantagens do trabalho remoto no Tribunal de Justiça do Estado do Amazonas.

Para melhor compreensão do objeto de estudo, inicialmente foram desenvolvidas revisões e pesquisas bibliográficas necessárias à pesquisa. Em seguida, desenvolveu-se uma pesquisa quantitativa, e os dados foram analisados a partir da estatística descritiva. Os temas abordados trataram sobre as relações familiares e profissionais desenvolvidas no mesmo espaço físico, convívio familiar e social, motivação para atividades extra laboral, saúde física e emocional, integração com a equipe de trabalho, isolamento social, permanência no regime de teletrabalho, expectativas e satisfação com o teletrabalho.

Importa relatar que os resultados obtidos demonstram que a grande maioria dos servidores em regime de teletrabalho do Tribunal de Justiça do Estado do Amazonas, respondentes à pesquisa, se sentem muito satisfeitos por estarem na modalidade remota e que estão conseguindo administrar as relações familiares e profissionais em suas residências. Como também, expressam 
Teletrabalho versos Qualidade de Vida: uma Abordagem sobre as Experiências Vividas por Servidores do Tribunal de Justiça do Estado do Amazonas

a satisfação no convívio familiar e social. Entretanto, um fato importante merece destaque, há servidores que estão pouco satisfeitos com os aspectos do convívio social, fato este que poderá acarretar em certos desligamentos do Programa de Teletrabalho. Importante ser dito que, embora muitos trabalhadores desejem entrar em teletrabalho, nem todos tem o perfil desejável ou adequado às características do Programa.

A pesquisa demonstra, ainda, que a maior parte dos teletrabalhadores que responderam à pesquisa estão muito motivados para desenvolverem atividades extra laboral, o que poderá contribuir para melhoria da saúde física e emocional. Já os resultados concernentes à integração do teletrabalhador com a equipe de trabalho apontam que os servidores da instituição que se encontram em teletrabalho, se sentem integrados na equipe, em níveis que vão de excelente a bom. Entretanto, uma pequena parte considera regular sua integração com a equipe. Este fato pesa muito para a obtenção dos resultados pretendidos pela gestão. A equipe integrada além de ser satisfatório para o servidor que se sentirá mais motivado, melhora a qualidade do serviço prestado, bem como proporciona maior celeridade no trato dos processos.

Salienta-se que, os resultados obtidos em relação ao tema isolamento social acende um alerta, pois, foi constatado que muitos se sentem algumas vezes isolados durante a realização das tarefas e atividades concernentes ao trabalho. A realização das tarefas laborais, em sistema home office, pode acarretar potenciais efeitos negativos na saúde ocupacional e bem-estar de alguns teletrabalhadores, por isso é muito importante assegurar uma boa comunicação entre o teletrabalhador, colegas e superiores, bem como, a área de gestão de pessoas deve manter contatos fraquentes, a fim de assegurar a saúde física e mental.

Quanto ao alcance das expectativas com o trabalho remoto, a grande maioria respondeu que suas expectativas foram totalmente alcançadas. Cada colaborador/servidor que se dispõe a ingressar em teletrabalho tem um objetivo e/ou expectativa a alcançar. Para uns pode ser estar mais presentes com a família, filhos, genitores, para outros $\mathrm{o}$ fato de estar longe dos congestionamentos, da poluição e violência urbana.

Destaque especial pode ser dado ao fato de que os teletrabalhadores questionados a respeito da permanência ou não em teletrabalho, pesando os prós e contras que a modalidade requer, a totalidade respondeu que prefere continuar executando suas atividades laborais no regime de teletrabalho.

O estudo demonstrou que houve melhorias na qualidade de vida dos servidores em teletrabalho do Tribunal de Justiça do Estado do Amazonas, visto que vários aspectos avaliados na pesquisa trouxeram resultados favoráveis, corroborando com os autores Vecchia et al (2005) que dizem que o conceito de qualidade de vida está diretamente associado à autoestima e ao bem-estar pessoal e compreende vários aspectos, como a capacidade funcional, o nível socioeconômico, o estado emocional, a interação social, o suporte familiar, a saúde, valores culturais, éticos e religiosos, o estilo de vida, a satisfação com o trabalho, e com o ambiente em que se vive. (Vecchia et al, 2005, p. 246). Conclui-se que há ganhos na qualidade de vida do servidor em teletrabalho, impactando assim positivamente na vida profissional e familiar, ainda, o teletrabalho promove vantagens de economia de tempo e redução de custos nos deslocamentos casa-trabalho, 
Teletrabalho versos Qualidade de Vida: uma Abordagem sobre as Experiências Vividas por Servidores do Tribunal de Justiça do Estado do Amazonas

bem como aumenta as possibilidades de trabalho aos servidores com dificuldade de locomoção. Em suma, o trabalho remoto, antes de ser um aspecto a ser controlado, possa ser um elemento que favoreça o desenvolvimento psicossocial e organizacional, mediante a produção coletiva de novas formas de trabalho.

Embora, a pesquisa desenvolvida apresente limitações e seus resultados não permitam fazer generalizações, espera-se ter contribuído para o enriquecimento do tema, assim como na decisão de se adotar ou não o teletrabalho como forma de realizar atividades laborais, e ainda, por conseguinte servir como fonte de consultas para futuras pesquisas.

\section{REFERÊNCIAS}

BVS - Biblioteca Virtual em Saúde do Ministério da Saúde. (2013). Dicas em Saúde - Qualidade de vida em 5 passos. Acesso em 24 de Maio de 2019, disponível em https://bvsms.saude.gov.br/bvs/dicas/260_qualidade_de_vida.html

Castells, M. (1999). A Sociedade em Rede (Vol. 1). São Paulo, São Paulo: Paz e Terra.

CNJ - Conselho Nacional de Justiça. (2016). Resolução $n^{o}$ 227/2016. Acesso em 17 de Maio de 2016, disponível em http://www.cnj.jus.br/busca-atos-adm?documento=3134

Ferreira Júnior, J. C. (jul/set de 2000). Telecommuting: o paradigma de um novo estilo de trabalho. RAE Light, 7(3), pp. 8-17.

Freitas, S. R. (s.d.). Teletrabalho na Administração Pública Federal - uma análise do potencial de implantação na Diretoria de Marcas do INPI. (Dissertação de Mestrado).

Administração Pública, Fundação Getúlio Vargas, Escola Brasileira de Administração, Rio de Janeiro, RJ, Brasil.

Goulart, J. O. (2009). Teletrabalho - alternativa de trabalho flexível. Brasília: SENAC.

Guimarães, M. d. (2009). Vida familiar e profissional: percepção das professoras de ensino superior da cidade de Manaus. (Tese de Doutorado). Faculdade de Filosofia, Ciências e Letras, Universidade de São Paulo. Ribeirão Preto, SP, Brasil.

Kramer, U., Burian, K., Gerbracht, P., \& Hegner, F. (2008). Wettbewerbsstärke und bessere Vereinbarkeit von Familie und Beruf - kein Widerspruch: flexible Arbeitszeiten in Kleinund Mittelbetrieben. Stuttgart: Kohlhammer.

Lima, M. S. (2018). O Teletrabalho no Poder Judiciário Brasileiro: ganhos para tribunais e sociedade? As experiências de Santa Catarina e Amazonas. (Dissertação de Mestrado). Administração Pública, Fundação Getúlio Vargas, Escola Brasileira de Administração, Rio de Janeiro, RJ.

Mello, Á. A. (1999). Teletrabalho (telework): o trabalho em qualquer lugar e em qualquer hora. São Paulo: Qualitymark.

Silva, R. T. (2004). O teletrabalho e suas influências na qualidade de vida no trabalho. (Tese de Doutorado). Universidade de São Paulo, São Paulo, SP, Brasil.

TJAM - Tribunal de Justiça do Estado do Amazonas. (2017). Resolução no 04/2017. Acesso em 18 de Maio de 2019, disponível em Diário da Justiça Eletrônico: www.tjam.jus.br/index.php/publicacoes-documentos/resolucoes-publicacoesdoc/resolucoes-publicacoes-phoca/file/12086 
Teletrabalho versos Qualidade de Vida: uma Abordagem sobre as Experiências Vividas por Servidores do Tribunal de Justiça do Estado do Amazonas

TJAM - Tribunal de Justiça do Estado do Amazonas. (8 de Maio de 2019). CNJ anuncia TJAM como vencedor do $1^{\circ}$ Prêmio de Práticas em Gestão de Pessoas do Poder Judiciário. Fonte: https://www.tjam.jus.br/index.php/menu/sala-de-imprensa/1407-cnj-anuncia-tjamcomo-vencedor-do-1-premio-de-praticas-em-gestao-de-pessoas-do-poder-judiciario

TJAM - Tribunal de Justiça do Estado do Amazonas. (2019). Resolução $n^{\circ}$ 08/2019. Acesso em 18 de Maio de 2019, disponível em Diário de Justiça Eletrônico: https://consultasaj.tjam.jus.br/cdje/consultaSimples.do?cdVolume=11\&nuDiario=2609\&c dCaderno $=1 \&$ nuSeqpagina $=15$

Vecchia, R. D., Ruiz, T., Bocchi, S. C., \& Corrente, J. E. (2005). Qualidade de vida na terceira idade: um conceito subjetivo. Revista brasileira de epidemiologia, 8(3), pp. 246-252. 